\title{
Review
}

\section{Dietary patterns, dietary nutrients and cardiovascular disease}

\author{
Paul J. Nestel ${ }^{1}$, Trevor A. Mori ${ }^{2}, *$ \\ ${ }^{1}$ Baker Heart and Diabetes Institute, 3004 Melbourne, VIC, Australia \\ ${ }^{2}$ Discipline of Internal Medicine, Medical School, University of Western Australia, 6000 Perth, WA, Australia \\ *Correspondence: trevor.mori@uwa.edu.au (Trevor A. Mori) \\ Academic Editors: Demosthenes B Panagiotakos and Matina Kouvari \\ Submitted: 14 October 2021 Revised: 26 November 2021 Accepted: 29 November 2021 Published: 14 January 2022
}

\begin{abstract}
A healthy dietary pattern can benefit multiple cardiovascular disease (CVD) risk factors. In conjunction with current standard-of-care pharmaceutical interventions it can provide an effective strategy for the prevention of CVD. Previous dietary recommendations have focused on targeting macronutrients. However, most of the recent international dietary guidelines now recommend a whole food, dietary pattern approach, whilst avoiding quantitative nutrient advice. The guidelines recommend: (1) increased intake of plant-based foods including complex, fibre-rich carbohydrates such as wholegrains, fruits and vegetables, but restricting the intake of refined starches; (2) substituting saturated fats with polyunsaturated and monounsaturated oils; (3) reducing salt intake; (4) increased fish consumption (or fish oils where applicable); (5) reducing sugar-sweetened drinks and added sugars; (6) avoiding butter and cream particularly in individuals at increased risk of CVD, but encouraging fermented products such as yoghurt; there is no specific advice on cheese and milk; (7) allowing consumption of lean meat in moderation but restricting processed meats; and (8) reducing cholesterol intake and foods rich in cholesterol (e.g., eggs and crustaceans) for those with diabetes and at increased CVD risk. The dietary guidelines should be adhered to in conjunction with low-to-moderate alcohol consumption, regular physical activity, avoiding tobacco and maintaining a healthy weight. This review summarises recently published research, international guidelines and position statements for minimizing CVD risk.
\end{abstract}

Keywords: Dietary patterns; Dietary recommendations; Cardiovascular risk; Type 2 diabetes; Plant based foods; Dietary fats; Carbohydrates; Fibre and sugar; Dairy foods; Meat consumption; Salt intake

\section{Introduction}

Healthful patterns of eating constitute an important cornerstone for preventing cardiovascular disease (CVD). Specific nutrients which have been shown to determine the impact of individual cardiovascular risk factors are more readily tested in randomized controlled trials (RCTs) whereas patterns of eating are derived from observational studies of large populations. The two approaches are complementary and have provided the evidence on which dietary guidelines have been based. Consumption of specific food groups are provided in qualitative terms which is more readily translatable than using quantitative measures. The 2019 Position Statements from the American College of Cardiology/American Heart Association (ACC/AHA) [1] and the European Society of Cardiology/European Atherosclerosis Society (ESC/EAS) [2] have adopted this stategy.

Principal recommendations include increased consumption of plant-based foods with fibre-rich complex carbohydrates collectively defined as "healthy" or "healthier" with respect to CVD prevention (e.g., vegetables, fruits, wholegrains, pulses) whilst restricting "less healthy" carbohydrate-rich foods (e.g., refined starches, sugars); reducing saturated fats and replacing with monounsaturated fatty acids (MUFA) and polyunsaturated fatty acids (PUFA); choosing reduced and low-salt products; maintain- ing a healthy bodyweight (partly through increased physical activity) and moderating alcohol consumption. Recommendations that have lesser evidential support include increasing intake of fish (or fish oils where indicated); reducing intake of butter and cream, but supporting intake of fermented dairy products (e.g., yoghurt, cheese); restricting processed meats but allowing lean meat in moderation; and reducing foods rich in cholesterol when CVD risk factors are raised. Variations in these recommendations have been made for different ethnic groups and for differing cultural preferences but have become public health policy across many nations [1-3].

An answer to the reliability of observational studies has been attempted by simulating a target trial of previously recommended dietary interventions in cohorts observed longitudinally. The 20 -year predictive risk of allcause mortality through implementation of AHA foodbased guidelines derived from the three largest US prospective studies of men [Health Professionals Follow-up Study (HPFS)] and women [Nurses' Health Study (NHS) and Nurses' Health Study II (NHS II)], was found to be only modestly dissimilar from the actual mortality data [4]. An important inference is that food-based dietary guidelines begun in mid-life do achieve beneficial outcomes through adherence to the principles of healthy eating.

Extensive information has been obtained from observational studies of long-term large prospective cohort stud- 
ies, with findings based on very large numbers derived over lengthy periods providing confidence in the conclusions. Notwithstanding, there are likely unknown confounders and methodological flaws in food frequency questionnaires and very importantly inadequate information about the total food pattern including foods substituted for candidate foods.

\section{Evaluation of dietary patterns}

The 2015 to 2020 Dietary Guidelines for Americans have recommended three similar dietary patterns: the Healthy US-Style Eating, the Healthy Mediterranean-Style Eating, and the Healthy Vegetarian Eating pattern $[5,6]$. Healthy dietary patterns emphasize increased intake of fruits, vegetables, whole grains, legumes and nuts in moderation. All include limited amounts of lean meat, fish, low- and non-fat dairy, and vegetable oils. They are low in saturated, trans and solid fats; salt (sodium); added sugars; and refined grains. Healthy dietary patterns should include appropriate energy intake and physical activity for maintaining a normal weight and achieving nutrient adequacy. The Diet to Stop Hypertension (DASH) [7] emphasises low-salt intake with a focus on reducing blood pressure. The Mediterranean diet is similar in composition to the abovementioned healthy diets but includes olive oil as the main source of fat. It is noteworthy, however, that there are regional variations in eating patterns within a Mediterranean diet. An Alternative Healthy Eating Index [8], has also been shown to associate with long-term trends in CVD in the Whitehall cohort from the UK [9].

The predictive strengths of the three major quantifiable healthy dietary patterns defined above: the Healthy US-Style Eating, the Healthy Mediterranean-Style eating and the Healthy Vegetarian Eating pattern [5,6], as well as the Alternative Healthy Eating Index [8], the Alternate Mediterranean Diet score [10] and the DASH diet $[7,11]$ have associated with an $8-22 \%$ reduction in allcause death $[10,12], 19-28 \%$ CVD death and $11-23 \%$ cancer death [13-16]. The US Nurses' Health Study $(47,994$ women) and the Health Professionals Follow-up Study $(25,745$ men) reported significantly lower CVD event rates over 12-years [17]. Hazzard Ratios (HR) for total mortality, predominantly CVD mortality, were 0.91 (95\% confidence interval $[\mathrm{CI}]: 0.85,0.97)$ for the Healthy Eating Index, 0.84 (95\% CI: 0.78, 0.91) for the Mediterranean Diet and 0.89 (95\% CI: 0.84, 0.95) for the DASH Diet. Evaluation of English public servants over 18-years through the Alternative Healthy Eating Index showed optimal adherence reduced CVD mortality by $42 \%$ [9]. The Spanish PREDIMED (PREvención con DIeta MEDiterránea) Mediterranean-style controlled study of the major components of healthy eating that included olive oil and nuts, reduced major CVD events (stroke, myocardial infarction, death from cardiovascular causes) [18].

Confounding factors, including sociodemographic and lifestyle factors, have been shown to influence interpretations [19]. Similar caution was expressed in a recent UK Biobank publication of a large cohort of 462,155 participants who were initially free from CVD [20]. Food intake was based on food-frequency responses. Familial predisposition from historical familial CVD in first-degree relatives and a polygenic risk score based on genome-wide association studies of a person's risk attributable to common variants that increase CVD risk, were taken into account. There were 46,164 cases of incident CVD available after a median 11.2-year follow-up. In accord with other (but not all studies) consumption of more frequent processed meat associated with a small increase in CVD risk (HR 1.07; 95\% CI: 1.03, 1.11; highest vs. lowest level) while consumption of fruit and vegetables, fish and cheese, were associated with modest decreased risk (respective HRs: 0.92 [95\% CI: 0.89, 0.96], 0.90 [95\% CI: 0.86, 0.94], 0.98 [95\% CI: $0.95,1.00]$ and 0.93 [95\% CI: 0.89, 0.96]). Stratification by polygenic risk score and familial predisposition for CVD risk altered these associations. Consumption of fish and cheese remained inversely related to incident CVD independently of familial predisposition, whereas a positive association between processed meat and CVD was evident only in individuals with a family history of CVD (HR 1.11; 95\% CI: 1.05, 1.16) [20].

The largest study assessing dietary patterns in relation to incident acute myocardial infarction was the INTERHEART Study, comprising 5761 cases and 10,646 controls from 52 countries [21]. A simple dietary risk score identifying an unhealthy eating pattern predominantly "Western style" (i.e., high in fried foods, salty snacks, eggs, meat) led to significantly more cases than dietary patterns regarded as healthier (e.g., high in fruit and vegetables).

The Mediterranean diet comprises mainly plant-based foods, as well as meat in moderation, fish and olive oil. However, the Mediterranean region includes highly variable eating patterns and differences within countries. The Spanish PREDIMED trial best illustrates the benefits of a Mediterranean pattern of eating [18]. In 7447 participants with no CVD at recruitment but at high risk of CVD, a Mediterranean diet that included extra-virgin olive oil or nuts led to a $30 \%$ and $28 \%$ reduction, respectively, in the incidence of major CVD events including stroke, after 4.8years. In contrast, a 2019 Cochrane Report [22] that included 30 RCTs comprising 12,461 participants, reported low-to-moderate evidence for clinical benefits for primary prevention and paucity of evidence for secondary prevention of a Mediterranean style eating pattern that included the PREDIMED Trial.

Several national surveys have reported that "ultraprocessed foods" are associated with an increased prevalence of cardiovascular risk. Such foods include formulations of macronutrients including fats, sugars, starches and protein isolates containing little whole food and often flavoured with additives [23]. These are mostly energy- 
dense containing extra sugars or salt and saturated fat generally packaged as snacks, soft drinks, processed meats and instant soups. The 2011-2016 National Health and Nutrition Examination Survey (NHANES) of 11,246 adults reported about one-half of the population's energy intake was derived from ultra-processed foods which showed a graded inverse association with cardiovascular health [24]. The Framingham Offspring Cohort during a follow-up from 1991 to 2014/2017 showed that CVD and coronary heart disease CHD events, and CVD and CVD deaths were increased by $7-9 \%$ for each 7.5 servings/day of ultraprocessed foods at baseline [25]. The Prospective Urban Rural Epidemiology (PURE) Study carried out in 21 countries and comprising 134,297 individuals of differing socioeconomic status and hence exposed to different sets of risk factors, reported a clear disadvantage with respect to CVD in countries with the greatest consumption of ultraprocessed meats [26]. During a 9.5-year follow-up, increased consumption of processed meat $(\geq 150 \mathrm{~g} /$ week vs. 0 $\mathrm{g} /$ week) was associated with an increased risk of total mortality (HR 1.51; 95\% CI: 1.08, 2.10) and major CVD (HR 1.46; 95\% CI: $1.08,1.98)$.

Possible mechanisms linking processing of many food groups to CVD is discussed by Juul et al. [27] to provide biological plausibility to the epidemiological observations. The question remains whether the term ultra-processed food simply describes one component of an "unhealthy" pattern of eating.

\section{Major food components of healthy dietary patterns}

\subsection{Plant based foods}

The simplest and most widely recommended key food group for CVD prevention are plant foods. A distinction has been made in recent years between "healthy" and "unhealthy" starches and carbohydrates which are the basic nutrients in plant foods. A study of 12,168 adults over a 30year period clearly showed different CVD outcomes among those preferentially eating "healthier" plant foods [28]. Such foods include fruits and vegetables, whole grains and pulses in contradistinction to "unhealthier" plant foods such as refined starches and grains, and sugar-sweetened drinks in particular. A follow-up of the Nurses' Health Study and the Health Professionals Follow-up Study spanning the period 1984-2013 and comprising 4,833,042 person-years confirmed the inverse association of a healthy plant-based diet and CHD (HR comparing the first and last decile 0.75; $95 \%$ CI: $0.68,0.83, p$-trend $<0.001$ ) [29]. In contrast, highest adherence to an unhealthy plant-based diet was directly associated with CHD (HR 1.32; 95\% CI: 1.20, 1.46, $p$ trend $<0.001$ ) [29]. Potato starches are frequently included as unhealthy because of their elevated glycaemic index. However, two recent prospective cohort studies comprising 69,313 Swedish men and women without CVD and diabetes followed-up over 13-years differed [30]. Total potato con- sumption did not associate with 10,147 major CVD events: multivariable HR per increments of three servings/week of total potato consumption were 1.00 (95\% CI: 0.97, 1.02) for major CVD events, 1.01 (95\% CI: 0.97, 1.04) for myocardial infarction, 0.97 (95\% CI: 0.93, 1.02) for heart failure, 1.01 (95\% CI: 0.97, 1.05) for stroke and 0.99 (95\% CI: 0.95 , 1.03) for CVD death [30].

Plant protein content has been claimed to improve blood pressure, blood lipids and glucose. An analysis that included 16,429 cardiovascular deaths among 715,128 individuals followed-up over 3.5 to 32 -years, showed a dosedependent inverse association with CVD death (HR 0.88; 95\% CI: $0.80,0.96, p=0.001$ ) [31]. All-cause deaths were reduced by $5 \%$ for every $3 \%$ energy increment from plant protein per day [31].

\subsection{Carbohydrates, fibre and sugar}

Dietary fibre, a major component of plant foods, undergoes a variable amount of fermentation in the bowel giving rise to partial or total absorption of solubilized products (soluble fibre), or resistance to full degradation (insoluble fibre). Examples of insoluble fibre include pectins, gums, celluloses, resistant starch. The data on the whole supports an inverse relationship between total dietary fibre and CVD as well as type 2 diabetes but is less certain with respect to the type of fibre. The large European Prospective Investigation into Cancer and Nutrition cohort (EPIC) included 452,717 individuals followed-up for 12.7-years [32]. Total dietary fibre was inversely related to circulatory disease (HRs per $10 \mathrm{~g}$ /day increments: 0.90 ; $95 \%$ CI: 0.84 , 0.97 in men and $0.88 ; 95 \%$ CI: $0.81,0.97$ in women). In a more recent study from France dietary fibre was evaluated in 107,377 participants [33]. Both soluble fibre and insoluble fibre were inversely related with CVD risk (HR for soluble fibre $0.80 ; 95 \% \mathrm{CI}: 0.66,0.98, p$-trend $=0.01$; for insoluble fibre HR $0.65 ; 95 \%$ CI: $0.45,0.94, p$-trend $=$ $0.02)$.

Carbohydrate "quality" can be defined by the carbohydrate-to-fibre ratio, with higher values implying lower fibre content. A combination of the Nurses' Health Study and the Health Professionals Follow-up Study (75,020 women and 42,865 men, respectively) reported 7320 incident cases of CHD [34]. Although the carbohydrate-to-total fibre ratio did not associate with incident CHD, the carbohydrate-to-cereal fibre ratio and the starch-to-cereal fibre ratio associated with an increased risk for incident CHD (20\% and 17\%, respectively). The findings were mainly due to a consistent inverse association between intake of cereal fibre and CHD [34]. These data accord with many studies showing a beneficial effect of whole grain cereals consumption. A meta-analysis comprising 14 prospective cohorts as well as data from the NHANES surveys, during which there were 23,957 CVD deaths, showed an inverse association between one $16 \mathrm{~g}$ daily serve of whole grains and CVD mortality (HR 0.91; $p<0.001)$ [35]. 
In the PREDIMED-Plus RCT carbohydrate quality (less readily digestible) rather than quantity determined cardiometabolic health [36]. Among 5373 overweight/obese Spanish adults with the metabolic syndrome, consumption of high quality carbohydrate compared with refined grains and starches and sugars, led to a reduction in waist circumference, blood glucose, triglycerides, glycated haemoglobin and blood pressure, and an increase in HDLcholesterol, after 12 months.

Pulses such as lentils, beans, peas and chickpeas contain $20-30 \mathrm{~g}$ fibre/100 g dry weight. They are slowly digested and reduce glycaemic index and cardiometabolic disorders [37]. Legumes generally (and pulses which are the dried equivalents as lentils, peas, chickpeas) trend to be inversely associated with incident CVD [37].

Certain specific foods that are fibre-rich in a minimally refined form such as oats and barley with high $\beta$ glucan content have been shown to modestly lower CVD risk by reducing LDL-cholesterol and improving glycaemic response. A recent analysis has shown that optimal responses in glucose and insulin secretion were achieved only with whole kernels and less so with thick flakes, but were not altered with thin/instant/quick oats compared with refined grain controls [38]. A further example of the effects of ultra-processing.

The optimal intake of carbohydrate was examined in the Atherosclerosis Risk in Communities study [39]. During a 25-year follow-up of 15,428 adults 45-64 years, there was a U-shaped relationship between the percentage of energy intake from carbohydrate and death. Both $<40 \%$ and $>70 \%$ energy associated with increased mortality; the lowest risk was observed at 50-55\% energy from carbohydrate. In a meta-analysis comprising 432,179 individuals, low $(<40 \%)$ and high $(>70 \%)$ carbohydrate consumption led to a higher risk of death than did moderate consumption, consistent with a U-shaped association (HR 1.20; 95\% CI: 1.09, 1.32 for low carbohydrate; 1.23 ; 95\% CI: $1.11,1.36$ for high carbohydrate) [39]. High carbohydrate intake has associated with an increase in plasma triglycerides and a reduction in HDL-cholesterol. Although LDL-cholesterol is minimally affected, the particle characteristics may be worse.

The chemical composition of starches, whether richer in amylose or amylopectin influence cardiometabolic risk in terms of predisposing to greater glycaemic responses [40]. Plant based foods are predominantly carbohydrate-rich yet are recommended as the base diet for diabetics. A review that discusses the role of such foods in preventing type 2 diabetes, their effectiveness and mechanisms is discussed in a recent perspective [41].

Of relevance also is the issue of low-carbohydrate diets that are replaced with fat and protein primarily for weight reduction. An analysis of 24,825 participants from NHANES surveys between 1999 and 2010 examined the effects of quartiles of low carbohydrate diets on total mortal- ity including deaths from CVD [42]. In addition, data were also obtained from 9 pooled prospective studies $(462,934$ individuals, 16.1-year mean follow-up). Low carbohydrate scores were directly related with total death (HR 1.22; 95\% CI: $1.06,1.39$ ) and CVD death (HR 1.13; 95\% CI: 1.02, 1.24 ) in the pooled studies and higher in the individual studies (HR 1.32; 95\% CI: 1.14, 2.01 and 1.51; 95\% CI: 1.19, 1.91 for total mortality and CHD mortality, respectively) comparing the highest versus the lowest low carbohydrate score.

Excess consumption of sucrose is generally regarded as ill-advised. NHANES surveys comprising 1988-2010 showed a dose-dependent increment in CVD mortality over 14.6-years among individuals consuming $>10 \%$ energy from added sugars (HR 1.30; 95\% CI: 1.09, 1.55) increasing to HR 2.75 (95\% CI: 1.40, 5.42) among those consuming 25\% [43]. Data from the Coronary Artery Risk Development in Young Adults (CARDIA) study in individuals 18-30 years at baseline showed at greater risk for incident type 2 diabetes in those who consumed the most sugar-sweetened beverages (SSB) [44]. One serve/day increased the risk of type 2 diabetes by $6 \%$. However, the CARDIA study also showed a similar increase in risk of type 2 diabetes (HR 1.12; 95\% CI: 1.04, 1.20) with artificially-sweetened beverage consumption [44]. Similarly, in a meta-analysis comparing CVD events between consumption of SSB (16,915 incident CVD cases, 18,042 CVD deaths) and low-calorie-sweetened beverages (LCSB) (18,077 incident CVD cases, 14,114 CVD deaths), a 1 serve/day increase in SSB associated with a significant dose-dependent $8 \%$ increased risk of incident CVD and CVD death [45]. A 1 serve/day increase in LCSBs associated with a 7\% increase risk of incident CVD but the relationship between LCSBs and CVD death was observed only at $>2$ serves/d [45].

A pan-European cohort study demonstrated the potential adverse effects of glucose loads based on glycaemic index [46]. In 338,325 individuals followed-up for 12.7years, energy-adjusted glucose load in the top quintile significantly increased the risk of CHD (HR 1.18; 95\% CI: $1.07,1.29$ for each $50 \mathrm{~g}$ of glycaemic load consumed daily). A recent report from the PURE Study investigators confirmed the association of the glycaemic index and glycaemic load (the index multiplied by the amount of glucose consumed) with CVD risk among 137,851 participants during a median follow-up of 9.5-years [47]. Comparing extreme quintiles a high glycaemic index related with a greater risk of a major cardiovascular event or mortality, in individuals with pre-existing CVD (HR 1.51; 95\% CI: 1.25, 1.82) and in those without such disease (HR 1.21; 95\% CI: 1.11, 1.34). 


\subsection{Dietary fats and fatty acids}

The optimal intake of fats and oils remains contentious. Current guidelines advise qualitative changes based on the characteristics of the oils and fats, and are consistent in recommending omega-6 PUFA and monounsaturated fats to substitute for some saturated (and most trans) fats and oils [1,2]. The intake of total fat is not strongly associated with increased risk of CVD other than being a major contributor of obesity.

Healthy eating patterns contain relatively small amounts of saturated fats. Notably, these diets, including the Mediterranean diet, include foods that associate with risk reduction. On the other hand, a large reduction in saturated fat can lead to a deficit of dairy foods, which in reduced-fat and fermented products, may be beneficial on CVD prevention (discussed later). A reduction in saturated fat consumption will lower LDL-cholesterol, although some of the benefit may relate to the substitution by unsaturated fats and other healthier food groups.

There has been much controversy regarding the optimal ratio of dietary carbohydrate-to-fat for the treatment of obesity and prevention of chronic diseases [48]. An analysis of the Nurses' Health Study (1980-2012) and the Health Professionals Follow-up Study (1986-2012) comprising 126,233 individuals over a period of 32-years, reported that substituting 5\% energy from carbohydrate with the equivalent PUFA and MUFA led to a fall in total and cardiovascular death with both fats but substantially more with PUFA [49]. Furthermore, comparing extreme quintiles, the HRs for total mortality were $1.08(95 \% \mathrm{CI}: 1.03,1.14)$ for saturated fat, $0.81(95 \% \mathrm{CI}: 0.78,0.84)$ for PUFA, 0.89 (95\% CI: 0.84, 0.94) for MUFA and 1.13 (95\% CI: 1.07 , 1.18 ) for trans-fat ( $p$-trend $<0.001$ for all). Total death was reduced by $27 \%$ and $13 \%$ when $5 \%$ of energy from saturated fats was replaced with equivalent energy from PUFA and MUFA, respectively. HR for total death comparing the upper and lower quintiles of n-6 PUFA intake (specifically of linoleic acid) was 0.85 (95\% CI: 0.81, 0.89), while marine $\mathrm{n}-3$ PUFA associated with a modest reduction in total death (HR 0.96; 95\% CI: 0.93, 1.00).

A systematic review and meta-analysis comprising 811,069 individuals with adequate food intake records and biomarker assessments has provided modest albeit significant support for a reduction in CVD through linoleic acid consumption [50]. Risk ratios (RR) for high versus low categories of linoleic acid intake were 0.87 (95\% CI: 0.81, 0.94) for total and 0.87 (95\% CI: 0.82, 0.92) for CVD death. A smaller Swedish study but with a lengthy follow-up also observed an inverse association between serum linoleic acid levels at baseline and incident CVD among men [51].

By contrast, evaluation of the associations between MUFA and CVD are difficult since these fatty acids are synthesized endogenously and are major fatty acids of many foods. Zong et al. [52] attempted to address this issue by investigating the relationships of plant and animal derived
cis-MUFA with the risk of CHD separately in the Nurses' Health Study (63,442 women) and the Health Professionals Follow-Up Study (29,942 men). When plant-based MUFA were modelled to isocalorically replace other macronutrients, the hazard ratio for CHD fell to 0.83 (95\% CI: 0.68 , $1.00)$ when substituted for saturated fats (5\% energy) and 0.86 (95\% CI: $0.76,0.97)$ for refined carbohydrates $(5 \%$ energy). By contrast, modelling animal-based MUFA for either saturated fats or refined carbohydrates for the same isocaloric substitutions, increased the HRs to 1.04 (95\% CI: $0.79,1.38)$ and 1.11 (95\% CI: 0.91, 1.35), respectively.

Similar findings for linoleic acid were also reported for incident type 2 diabetes from a 10-nation collaboration comprising 20 cohort studies [53]. In this analysis comprising 39,740 adults without type 2 diabetes at baseline, biomarkers of linoleic acid consumption were derived from the linoleic acid content within multiple plasma lipid species. Linoleic acid levels were shown to be inversely related to incidence of type 2 diabetes (RR 0.57 ; 95\% CI: $0.51,0.64$, for the top vs. bottom quintile).

A systematic review examining the relationship between dietary fat with the metabolic syndrome and/or its components showed an inverse relationship with MUFA and PUFA, and a positive association with saturated fat [54]. The authors concluded that dietary recommendations should not be to avoid fats, rather to qualify what kind of fat is preferable to consume through a healthy diet and lifestyle.

\subsection{Dietary cholesterol}

The approach to dietary cholesterol has undergone changes, in particular advice relating to egg consumption. The current ACC/AHA guideline [1] has also abandoned restriction to $200-300 \mathrm{mg} /$ day equivalent to one egg. It is less prescriptive stating: "A diet containing reduced amounts of cholesterol and sodium can be beneficial to decrease atherosclerotic cardiovascular disease (ASCVD) risk.". The 2020 AHA Science Advisory on Dietary Cholesterol and Cardiovascular Risk has adopted a similar approach [55].

It is well accepted that there is a positive association between LDL-cholesterol levels and CVD and a similar direct correlation between intake of cholesterol and LDL-cholesterol. However, observational studies have not consistently demonstrated an association between cholesterol intake with CVD. Although RCTs have documented a dose-dependent increase in LDL-cholesterol when cholesterol is consumed (remembering that apart from eggs, substantial cholesterol is present in crustaceans, cheese, brains, etc.), there remains reluctance to support a more restrictive advisory. The possible mechanisms for the hyper-responder/hypo-responder findings have been recently summarized and likely relate to the presence of different isoforms of the apolipoprotein E phenotype and other genetic variations in the endogenous homeostasis of cholesterol through a balance between the reciprocal effects of ab- 
sorption and synthesis [56]. The inter- and intra-individual variations can be quite large even in highly compliant individuals and unless understood can undermine the health message.

The AHA Advisory [55] points to the common association between foods rich in both cholesterol and saturated fat, fatty meats and processed meats for instance, proposing that advice to commit to a healthy diet ensures reduced intake of foods high in saturated fat that include cholesterol. It is noteworthy, however, that the AHA Advisory states: "Patients with dyslipidemia, particularly those with diabetes mellitus or at risk for heart failure, should be cautious in consuming foods rich in cholesterol." [55].

Much of the confusion around egg consumption has stemmed from the fact that eggs and in particular egg yolks, contain cholesterol. Eggs are the main source of cholesterol in the diet. The number of eggs eaten per unit time has been a common indicator of cholesterol intake. The AHA [55] statement is based on two reports relating a positive association between increased egg consumption with CHD, and a recent meta-analysis from six prospective US cohorts totalling $>29,000$ participants, that show dose-dependent increments in all-cause deaths and risk of incident CVD with just half-an-egg per day [57]. Consumption of one egg per day associated with a $12 \%$ increased risk of CVD and $16 \%$ mortality. In contrast, the Pan-European EPIC cohort ( $>400,000$ individuals) [58], and the PURE study comprising 50 populations $(>145,000$ individuals) with additional data from 31,544 patients with vascular disease from two drug trials [59], did not show a relationship between consumption of eggs and CVD. A recent meta-analysis involving 24 prospective cohort studies did not find an association between egg consumption and the risk of stroke (RR 0.92; 95\% CI: $0.84,1.01$, for the top vs. bottom quintiles of egg consumption) [60]. Subgroup analysis, however, showed increased egg consumption associated with a significantly reduced incidence of stroke in Asia, but not in North America or Europe. There was also a non-linear relationship: $1-4$ eggs/week associated with decreased risk, whereas $>6$ eggs/week increased the risk of stroke.

Data from 3 large US prospective cohorts over 30 years comprising 5,529,959 person-years and 20,514 incident cases of type 2 diabetes, show a 14\% increased risk for diabetes with each egg consumed daily [61]. However, there were differences by geographic region: one egg daily associated with a significantly increased risk of diabetes in US studies (RR 1.18; 95\% CI: 1.10, 1.27), but not in European or Asian studies. Further support was reported in a 13.3-year follow-up of 46,263 women participating in the Women's Health Initiative, which showed positive associations between egg cholesterol and total dietary cholesterol with diabetes [62]. The study showed a $22 \%$ increased risk of diabetes with $\geq 3$ eggs consumed per week, and $23 \%$ and $31 \%$ increased risk for cholesterol consumption in the 4 th and 5 th quintiles, respectively.
The AHA statement [1] does not include targets for cholesterol consumption, but appears appropriate in recommending a CVD healthy dietary pattern whilst limiting egg consumption only for individuals at increased risk of CVD including diabetics. Others have suggested that individuals with diabetes should limit their consumption to no more than 7 eggs/week due to the greater risk associated with developing CVD [63]. The ESC/EAS guideline [2] recommends $<300 \mathrm{mg}$ cholesterol/day for individuals with hypercholesterolaemia.

\subsection{Fish and fish oils}

Several decades of controversy have still not resolved the question whether eating fish or consuming omega-3 PUFA protect against CVD. Several reviews and metaanalyses have at least agreed that clinical trials in which both eicosapentaenoic acid (EPA) and docosahexaenoic acid (DHA) were tested in amounts of approximately 1 $\mathrm{g} /$ day failed to show benefit [64].

Several recent trials have assessed the efficacy of omega-3 PUFA on cardiovascular endpoints. The MERLIN-TIMI 36 trial tested for a possible benefit of circulating omega-3 PUFA in 6560 individuals hospitalized with acute coronary syndromes and non-ST-segment elevation, in terms of progression to myocardial infarction and cardiac complications including deaths [65]. The trial showed long-chain $\omega 3$ PUFA associated with $18 \%$ lower incidence of cardiovascular mortality that was primarily driven by a $27 \%$ reduced incidence of sudden cardiac death. A larger intervention dose of $1.8 \mathrm{~g}$ /day EPA + DHA was tested in elderly men and women who had recently sustained an acute myocardial infarct [66]. The OMEMI trial (Omega-3 Fatty acids in Elderly with Myocardial Infarction) a multicentre RCT in 1027 patients, found no reduction in clinical events from consuming fish oil after a 2-year follow-up.

Two recent trials increased the dose of fish oil to 4 $\mathrm{g} /$ day and extended the period of follow-up. The REDUCEIT trial (Reduction of Cardiovascular Events with Icosapent Ethyl-Intervention Trial) was carried out in a highrisk population mainly secondary prevention in nature [67]. This multicentre RCT included 8179 individuals with established CVD or diabetes and other risk factors. At baseline they were taking statins and had raised fasting triglycerides $(1.52-5.63 \mathrm{mmol} / \mathrm{L})$ but normal LDL-cholesterol levels $(1.06-2.59 \mathrm{mmol} / \mathrm{L})$. Participants were randomized to $4 \mathrm{~g}$ /day of purified EPA (icosapent ethyl) or a mineral oil. The treated group showed a $25 \%$ reduction in the primary endpoint (a composite of cardiovascular death, nonfatal myocardial infarction, nonfatal stroke, coronary revascularization, or unstable angina) and a $26 \%$ reduction in the secondary endpoint (a composite of cardiovascular death, nonfatal myocardial infarction, or nonfatal stroke) after a median follow-up of 4.9-years. Subsequent analyses showed treatment reduced total (first and subsequent) is- 
chaemic events for the primary and secondary endpoints by $30 \%$ and $28 \%$, respectively [68]. The benefit of EPA confirmed an earlier open-label blinded trial using $1.8 \mathrm{~g} /$ day EPA as ethyl ester [69]. The Japan EPA Lipid Intervention Study (JELIS), which randomised 18,645 Japanese participants with hypercholesterolaemia to a low-intensity statin therapy plus $1.8 \mathrm{~g}$ /day EPA or statin therapy alone, showed major CHD events were reduced by $19 \%$ at a mean followup of 4.6-years.

By contrast, the recent Long-Term Outcomes Study to Assess Statin Residual Risk with Epanova in High Cardiovascular Risk Patients with Hypertriglyceridemia (STRENGTH) also tested $4 \mathrm{~g}$ /day fish oil in 13,078 patients randomised to either combined EPA + DHA in a free fatty acid formulation or placebo, in a population with high plasma triglycerides but with fewer secondary prevention patients than were enrolled in REDUCE-IT [70]. It was stopped for futility after 2-year and showed no significant reduction in the composite outcome of major adverse cardiovascular events. A minor difference between the two trials was in the placebo groups who were given a mineral oil in REDUCE-IT and vegetable oil in STRENGTH, an issue which has been largely dismissed [71], although the placebo group in the REDUCE-IT trial experienced a 10\% increase in LDL-cholesterol [67]. The main question that is unresolved is whether DHA may be counter-productive and that EPA alone is the preferred fatty acid. Possible biological differences between EPA and DHA which can result in different bioactive compounds have been proposed [72]. Both fatty acids improve cardiovascular biomarkers, with some reports that DHA ( $4 \mathrm{~g} /$ day) may in fact have a greater effect on blood pressure and vascular function $[73,74]$. Further, a comparison of omega-3 carboxylic acids versus corn oil in the STRENGTH trial examined the associations of the top tertiles of each fatty acid in plasma, finding that neither influenced CVD events in these high-risk participants [75].

Notwithstanding the counter arguments relating to EPA versus DHA, recent meta-analyses have reported fewer cardiovascular events with higher doses of omega3 PUFA. A meta-analysis of 13 RCTs comprising 124,477 participants, including those from REDUCE-IT, showed a dose-dependent relationship between intake of omega-3 PUFA and cardiovascular outcomes [76]. Inverse associations for all outcomes were attenuated but remained significant after excluding REDUCE-IT. Another meta-analysis totalling 149,051 participants from 38 RCTs also concluded that omega-3 oils reduced CVD mortality (RR 0.93; 95\% CI: $0.88,0.98)$ and non-fatal myocardial infarction (RR 0.87; 95\% CI: 0.81, 0.93), as well as CHD (RR 0.91; 95\% CI: 0.87, 0.96), major adverse cardiovascular events (RR 0.95; 95\% CI: 0.92, 0.98), and revascularization (RR 0.91; 95\% CI: 0.87, 0.95) [77]. Inclusion of REDUCE-IT data provided the most support. However, the incidence of atrial fibrillation increased (RR 1.26; 95\% CI: 1.08, 1.48). Similar undesirable effects on atrial fibrillation by omega-3
PUFA were reported in a meta-analysis of 8 trials comprising 83,112 patients [78].

Although highly recommended, it remains less certain whether eating more fish, particularly oily fish, is as effective for cardiovascular prevention. A meta-analysis of 34 meta-analyses of cohort studies provided moderate quality support for fish consumption; there was a dose-related fall in all-cause death with every $100 \mathrm{~g} /$ day increase in fish intake [79]. Each $100 \mathrm{~g} /$ day increment in fish consumption also associated with a $25 \%$ reduced risk of cardiovascular death and myocardial infarction, 12\% lower CHD, 14\% lower stroke and $20 \%$ lower heart failure. A 58 nationwide survey comprising 191,558 individuals reported that eating $175 \mathrm{~g} /$ week (approx. 2 servings) of fish with increased amounts of omega-3 PUFA was associated with a reduced risk of major CVD events and total death among high-risk individuals or patients with existing vascular disease but not in the general population [80]. In some parts of the world contaminants of various types from chemicals to indigestible particulate debris have caused anxiety about the safety of eating fish. The reader is referred to the relevant health information for further safety data.

\subsection{Dairy foods}

A major change in attitude and advice from health authorities relates to the inadvisability of consuming dairy food that arose from general guidance to avoid fatty foods with high-saturated fatty acid content. Only recently has advice regarding dairy intake taken into account the whole food and the compositional variety in the matrix of individual products. Such recognition has modified attitudes while not entirely dismissing the significance of the fat content.

An analysis of 12 meta-analyses [81] concluded that intake of total dairy products, containing either regular- or low-fat, or with different dose-responses, showed no relationship or lower risk of total incidence and mortality for CVD, CHD, and ischaemic and haemorrhagic stroke. Further, fermented milks (i.e., yogurt, cheese) decreased biomarkers of CVD risk [81]. A meta-analysis of 31 cohort studies showed an inverse trend between total dairy consumption and CVD and fatal and non-fatal CHD, which appears to have been driven by intake of cheese (HR 0.86; 95\% CI: $0.79,0.94$ for each $600 \mathrm{~g}$ /day of total dairy and 0.86; 95\% CI: $0.75,0.97$ for each $50 \mathrm{~g}$ /day cheese intake) [82]. High-fat dairy food tended to be positively associated with CHD whereas low-fat total dairy was inversely associated (HR 0.90; 95\% CI: 0.82, 0.98). In contrast, another analysis of 24 cohort studies failed to observe any effect of total dairy consumption on fatal and non-fatal CHD events [83]. Surprisingly, the effect of total dairy on stroke was more striking than on CHD: one study showed total dairy intake, both full-fat and low-fat dairy, to be significantly and inversely related with total stroke (HR 0.91; 95\% CI: $0.83,0.99$ ) [82]. As with CHD, cheese consumption was significantly inversely related with total stroke (HR 0.87 ; 
$95 \%$ CI: 0.77, 0.99) [82]. Cheese consumption was also inversely related with stroke in each of 5 meta-analyses [81]. Butter was not associated with CVD but the amounts consumed were small and interpretations based on increments of 10-14 $\mathrm{g} /$ day [81].

In one of the largest meta-analyses of 29 prospective cohort studies including 928,465 participants of whom about one-tenth died, 28,419 suffered incident CHD events and 25,416 CVD events, there were no associations observed with total dairy or milk intake whether of low-fat or high-fat variety [84]. This meta-analysis also showed a modest but significant inverse relationship between total fermented dairy products (yogurt, cheese, fermented milk; per $20 \mathrm{~g} /$ day) with mortality and CVD risk (both HR 0.98; 95\% CI 0.97, 0.99), but not for CHD [84]. The 12-year follow-up of the Alpha Omega Cohort from the Netherlands, that included 48,473 person-years and 2035 deaths, was consistent with other findings that yogurt consumption was inversely related with CVD death (HR 0.96 ; $95 \% \mathrm{CI}$ : $0.93,0.99$, per $25 \mathrm{~g} /$ day) and all-cause death (HR $0.98 ; 95 \%$ CI: $0.96,1.00$, per $25 \mathrm{~g} /$ day) in patients with a history of myocardial infarction [85].

The foods that substitute when dairy intake is reduced or increased need also to be considered. Attenuation in CVD risk occurred when dairy food was replaced by unsaturated oil and wholegrain foods but not by trans-fats or refined carbohydrates [86]. Similar conclusions were drawn from three US prospective cohorts comprising 5,158,337 person-years who experienced 8974 CHD and 14,815 CVD events [87]. Dairy consumption in comparison with equivalent energy from carbohydrates (excluding fruit and vegetables), was not associated with total CVD events including both CHD and stroke. However, event rates were reduced when dairy fat was partially substituted by polyunsaturated fat $(5 \%$ energy substitution led to a calculated $24 \%$ reduction in CVD risk) and by whole-grain foods, but not by refined carbohydrates or animal fats, the latter increasing risk by $6 \%$. In another US study that included 36,364 personyears of follow-up, full-fat dairy was inversely related with subsequent CVD risk whereas meat fat was positively associated [88].

The issue of fat content was not resolved by the abovementioned meta-analyses since there were reports of lower HR for CHD and stroke with low-fat dairy in some but the converse or no difference in others. In individual population studies, the findings also differed for total dairy although there was generally agreement for a potential benefit of fermented dairy foods. One of the largest prospective cohorts is the Pan-European EPIC cohort reporting on 409,885 individuals from 9 countries who experienced 7198 CHD events during 12.6-years [58]. The two fermented dairy foods yogurt and cheese were inversely associated with CHD events (yogurt HR 0.93; 95\% CI: 0.89, 0.98 , per $100 \mathrm{~g}$ /day increments; cheese HR $0.92 ; 95 \% \mathrm{CI}$ : $0.86,0.98$, per $30 \mathrm{~g}$ /day increments). Similar findings were reported in the Danish Diet, Cancer and Health Study of 54,903 individuals prospectively followed 15.9-years [89]. The risk of myocardial infarction was lower when low-fat or whole-fat milk was partially substituted by yogurt (HR 0.89; $95 \%$ CI: $0.80,0.99$ and 0.87 ; $95 \%$ CI: $0.78,0.98$, respectively for each $200 \mathrm{~g}$ /day replaced); or cheese (HR 0.96; $95 \%$ CI: $0.92,0.99$ and 0.95 ; $95 \%$ CI: $0.89,0.99$, respectively for every $20 \mathrm{~g}$ /day substituted for $200 \mathrm{~g} /$ day either full-fat or low-fat milk). In contrast to reports of a benefit or no effect of dairy on CVD, the recently published follow-up of 102,521 post-menopausal women in the Women's Health Initiative $(1,876,205$ person-years, including 6993 deaths from CVD), showed a positive relationship between total dairy protein consumption and CVD risk (HR 1.11; 95\% CI: $1.02,1.22)$ [90].

A recurring problem in nutritional epidemiology is determining the effect of the foods displaced by dairy. This issue was addressed in the Australian Longitudinal Study on Women's Health that also reported lower CVD risk among 7679 women free of CVD at baseline [91]. Women consuming large amounts of dairy especially yogurt and total fermented dairy products had a $16 \%$ lower CVD risk during a 15-year follow-up, however, significance was diminished when other food components and total energy intake were taken into account.

In a Mendelian randomization analysis from Northern Sweden, using a lactase single nucleotide polymorphism (an index of diary consumption), individuals that consumed non-fermented milk $\geq 2.5$ times/day experienced a $32 \%$ higher risk in all-cause death compared with those who consumed milk $\leq 1$ time/week [92]. All types of non-fermented milk-fat independently associated with higher HRs, but compared with full-fat milk, HRs were lower in those that consumed medium- and low-fat milk. Intake of fermented milk and cheese lowered risk (HR 0.90; 95\% CI: 0.86, 0.94 and 0.93 ; 95\% CI: 0.91, 0.96, respectively), whereas butter increased risk (HR 1.11; 95\% CI: 1.07, 1.21). These findings confirmed a previous report from the Swedish Mammography Cohort that included 33,636 women in whom there was a $34 \%$ higher CHD risk with butter intake whereas cheese was inversely related (HR $0.74 ; 95 \%$ CI: $0.60,0.91$ ) [93].

It is recognized that some individuals develop abdominal bloating and diarrhoea after consuming dairy foods. This is occasionally due to lactose intolerance or the fermentation of lactose as part of excessive fermentation of other foods and manifesting as irritable bowel syndrome but this issue will not to be reviewed here.

\subsection{Meat consumption}

The controversy relating to the consumption of meat has not abated. Recently amended advice is to limit the intake to small amounts of lean meat, which is low in saturated fat and not to be consumed on a daily basis. There appears to be greater agreement to limit consumption of processed meats that are high in fat and salt. 
Some observational studies have shown an association between consumption of meat and risk of CVD, one of the largest being the EPIC Study from Europe [58]. During a 12.6-year follow-up, 7198 of the 409,885 participants experienced a myocardial infarction. Individuals in the top quintile had a $13 \%$ higher risk for infarction for total meat intake and $10 \%$ increased risk for processed meat and red meat [58]. Consumption of red meat in the top quintile was 94 g per day; smaller amounts did not associate with excess risk. The majority of studies have distinguished fresh meat from processed meats and concluded that processing increases the risk for CVD which is likely related to its increased fat and salt content $[94,95]$. A meta-analysis comprising 1,218,380 participants and 23,889 CHD events reported no relationship between unprocessed meat and CHD, whereas processed meat associated with a $42 \%$ increased risk of CHD for $50 \mathrm{~g}$ serving per day [96].

Lower all-cause mortality was observed in another study when plant protein at 3\% energy replaced an equivalent amount of protein from processed red meat (HR 0.66; $95 \% \mathrm{CI}: 0.59,0.75$ ) or unprocessed meat (HR 0.88; $95 \% \mathrm{CI}$ : $0.84,0.92$ ) [97]. In the Adventist Health Study 2 comprising 55,851 participants, consumption of 0-24 g/day, 25-69 $\mathrm{g} /$ day and $\geq 70 \mathrm{~g} /$ day of meat increased the risk of incident type 2 diabetes by $29 \%, 42 \%$ and $65 \%$, respectively [98]. A study that analysed individual-level data from 29,682 participants in 6 prospective US cohort studies showed unprocessed meat and processed meat were related with small but significant increments in incident CVD (HR 1.07; 95\% CI: 1.04; 1.11 and 1.03; 95\% CI: 1.01, 1.06, respectively) [99]. Environmental concerns have led to individuals avoiding meat consumption but this issue will not be reviewed further.

\subsection{Salt intake}

All major dietary guidelines advise the general population and those with hypertension especially to reduce salt intake $[1,2]$. In most populations consumption of excess salt is the main dietary contribution to elevated blood pressure and consequently to cardiovascular morbidity [100]. There is a clinically significant dose-response relation between salt restriction and blood pressure that is particularly evident in hypertensives $(-7.7 /-3.0 \mathrm{mmHg} / 100 \mathrm{mmol}$ for systolic/diastolic blood pressure) compared with normotensives $(-1.46 /-0.07 \mathrm{mmHg} / 100 \mathrm{mmol})$ [101]. In a metaanalysis including 133,118 individuals $(63,559$ hypertensive and 69,559 normotensive), those with hypertension and a sodium intake of $>7 \mathrm{~g} /$ day had a $23 \%$ increased risk of cardiovascular events and death over a median of 4.2years [102]. Other observational cohort studies have shown a significant relationship between sodium consumption and all stroke (RR 1.24; 95\% CI: 1.08, 1.43), fatal stroke (RR 1.63; 95\% CI: $1.27,2.10)$ and fatal CHD events (RR 1.32; $95 \%$ CI: 1.13, 1.53) [100]. The blood pressure response varies across individuals and about $25 \%$ of normotensives are defined as being salt sensitive [103]. In contrast, many hypertensive individuals are salt sensitive and have a high intake of salt [103].

The blood pressure lowering effect of antihypertensive medications can be enhanced by avoiding added salt and salt-rich foods in a pattern of eating according to the DASH diet [104]. A high potassium intake can also enhance the blood pressure lowering effects of sodium restriction [105]. A recently published trial conducted in a cohort of 20,995 persons recruited from 600 villages in China confirmed the benefit of substituting $25 \%$ of salt intake with a salt substitute [106]. During a 4.7-year follow-up, the rates of stroke (RR 0.86; 95\% CI: 0.77, 0.96; [29.14 events vs. 33.65 events per 1000 person-years]), major cardiovascular events (RR 0.87; 95\% CI: $0.80,0.94$ ) and death from any cause (RR $0.88 ; 95 \% \mathrm{CI}: 0.82,0.95$ ), were significantly lower with the salt substitute than with regular salt.

\subsection{Other nutrients}

The influence of commonly eaten nutrients on CVD outcomes remains confused. A review from the USA comprising 992,129 participants showed folic acid was related with a $20 \%$ reduced risk for stroke; calcium plus vitamin D increased the risk for stroke by $17 \%$ [107]. Other supplements, including vitamin B6, vitamin A, multivitamins, antioxidants and iron did not associate with CVD outcomes or death [107]. The data supporting those conclusions contrast with the findings from the 1999 and 2010 NHANES surveys in 20,602 adults aged $\geq 30$-years who were followed up to the end of 2015 [108]. Nutrient adequacy was determined by percent of Recommended Dietary Intake (RDA) or Adequate Intake (percent of AI) as appropriate. Outcomes were total mortality and CVD deaths. Higher vitamin E, magnesium, iron, dietary fibre and potassium intake relative to the RDA/AI were all associated with reduced all-cause death. Higher vitamin A intake associated with fewer CVD deaths (HR 0.75; 95\% CI: 0.57, 0.99) and cancer (HR 0.76; 95\% CI: $0.62,0.94)$. Higher consumption of EPA + DHA and essential amino acids was inversely associated with lower risk of CVD and all-cause mortality [108]. These somewhat unexpected results appear to be due to the method of calculating under- and overconsumption relative to RDA and AI which is legitimate but difficult to compare with other studies.

\section{Conclusions}

Current evidence highlights the benefits of a healthy dietary pattern in lowering the risk of future CVD. A diet consisting of fruits, vegetables, and whole grains is recommended. Plant-based proteins are the preferred sources of protein followed by fish and poultry. A healthy dietary pattern should minimize consumption of refined starches, added sugars (including sugar-sweetened drinks), transfats, red meats (particularly processed meats) and sodium (salt intake). Saturated fats should be replaced with polyun- 
saturated and monounsaturated oils. Consumption of dairy is supported (without strong evidence to favour reduced-fat products), in particular fermented dairy such as yoghurt and cheese, but avoiding butter and cream principally in individuals with diabetes or at increased risk of CVD. Cholesterol and foods high in cholesterol, including eggs and crustaceans, should be limited for individuals with diabetes or those at increased risk of CVD. A healthy dietary pattern in conjunction with low-to-moderate alcohol consumption, regular physical activity, and avoidance of adiposity and tobacco, will attenuate future risk of CVD with likely similar benefits for other chronic disease conditions.

The challenge is for individuals and populations at large to adopt this guidance. The media often provides mixed nutritional information that is difficult to understand and apply, and is dominated by powerful food marketing that particularly impacts children. The responsibility rests equally with healthcare practitioners, industry and governments to instigate strategies that will lead to a sustained healthy lifestyle for all populations.

\section{Author contributions}

PJN and TAM-performed the literature search, drafted and critically revised the manuscript.

\section{Ethics approval and consent to participate}

All reported studies with human subjects performed by the authors have been published and complied with ethical standards including the Helsinki declaration and its amendments, institutional/national research committee standards and international/national/institutional guidelines.

\section{Acknowledgment}

Not applicable.

\section{Funding}

Funding to support a Senior Fellowship for TAM from the National Health and Medical Research Council of Australia (ID 1136046) is greatly appreciated.

\section{Conflict of interest}

The authors declare no conflict of interest.

\section{References}

[1] Arnett DK, Blumenthal RS, Albert MA, Buroker AB, Goldberger ZD, Hahn EJ, et al. 2019 ACC/AHA Guideline on the Primary Prevention of Cardiovascular Disease: A Report of the American College of Cardiology/American Heart Association Task Force on Clinical Practice Guidelines. Circulation. 2019; 140: E596-E646.

[2] Mach F, Baigent C, Catapano AL, Koskinas KC, Casula M, Badimon L, et al. 2019 ESC/EAS Guidelines for the management of dyslipidaemias: lipid modification to reduce cardiovascular risk. European Heart Journal. 2020; 41: 111-188.

[3] National Health and Medical Research Council (2013)
Australian Dietary Guidelines. 2013. Available at: https://www.eatforhealth.gov.au/sites/default/files/files/th e_guidelines/n55_australian_dietary_guidelines.pdf (Accessed: 16 September 2021)

[4] Chiu YH, Chavarro JE, Dickerman BA, Manson JE, Mukamal $\mathrm{KJ}$, Rexrode KM, et al. Estimating the effect of nutritional interventions using observational data: the American Heart Association's 2020 Dietary Goals and mortality. The American Journal of Clinical Nutrition. 2021; 114: 690-703.

[5] Freeman AM, Morris PB, Barnard N, Esselstyn CB, Ros E, Agatston A, et al. Trending Cardiovascular Nutrition Controversies. Journal of the American College of Cardiology. 2017; 69: $1172-1187$.

[6] 2015-2020 Dietary Guidelines for Americans. U.S. Department of Health and Human Services and U.S. Department of Agriculture. 2015-2020 Dietary Guidelines for Americans. 8th Edition. December 2015. Available at http://health.gov/dietaryguidelines /2015/guidelines/ (Accessed: 16 September 2021).

[7] Filippou CD, Tsioufis CP, Thomopoulos CG, Mihas CC, Dimitriadis KS, Sotiropoulou LI, et al. Dietary Approaches to Stop Hypertension (DASH) Diet and Blood Pressure Reduction in Adults with and without Hypertension: a Systematic Review and Meta-Analysis of Randomized Controlled Trials. Advances in Nutrition. 2020; 11: 1150-1160.

[8] Chiuve SE, Fung TT, Rimm EB, Hu FB, McCullough ML, Wang $\mathrm{M}$, et al. Alternative Dietary Indices both Strongly Predict Risk of Chronic Disease. The Journal of Nutrition. 2012; 142: 1009 1018.

[9] Lagström H, Stenholm S, Akbaraly T, Pentti J, Vahtera J, Kivimäki M, et al. Diet quality as a predictor of cardiometabolic disease-free life expectancy: the Whitehall II cohort study. The American Journal of Clinical Nutrition. 2020; 111: 787-794.

[10] Fung TT, Rexrode KM, Mantzoros CS, Manson JE, Willett WC, Hu FB. Mediterranean Diet and Incidence of and Mortality from Coronary Heart Disease and Stroke in Women. Circulation. 2009; 119: 1093-1100.

[11] Fung TT, Chiuve SE, McCullough ML, Rexrode KM, Logroscino G, Hu FB. Adherence to a DASH-Style Diet and Risk of Coronary Heart Disease and Stroke in Women. Archives of Internal Medicine. 2008; 168: 713-720.

[12] Schwingshackl L, Hoffmann G. Diet Quality as Assessed by the Healthy Eating Index, the Alternate Healthy Eating Index, the Dietary Approaches to Stop Hypertension Score, and Health Outcomes: a Systematic Review and Meta-Analysis of Cohort Studies. Journal of the Academy of Nutrition and Dietetics. 2015; 115: 780-800.e5.

[13] George SM, Ballard-Barbash R, Manson JE, Reedy J, Shikany $\mathrm{JM}$, Subar AF, et al. Comparing Indices of Diet Quality with Chronic Disease Mortality Risk in Postmenopausal Women in the Women's Health Initiative Observational Study: Evidence to Inform National Dietary Guidance. American Journal of Epidemiology. 2014; 180: 616-625.

[14] Harmon BE, Boushey CJ, Shvetsov YB, Ettienne R, Reedy J, Wilkens LR, et al. Associations of key diet-quality indexes with mortality in the Multiethnic Cohort: the Dietary Patterns Methods Project. The American Journal of Clinical Nutrition. 2015; 101: $587-597$.

[15] Liese AD, Krebs-Smith SM, Subar AF, George SM, Harmon BE, Neuhouser ML, et al. The Dietary Patterns Methods Project: Synthesis of Findings across Cohorts and Relevance to Dietary Guidance. The Journal of Nutrition. 2015; 145: 393-402.

[16] Reedy J, Krebs-Smith SM, Miller PE, Liese AD, Kahle LL, Park Y, et al. Higher Diet Quality is Associated with Decreased Risk of all-Cause, Cardiovascular Disease, and Cancer Mortality among Older Adults. The Journal of Nutrition. 2014; 144: 881-889.

[17] Sotos-Prieto M, Bhupathiraju SN, Mattei J, Fung TT, Li YP, Pan A, et al. Association of Changes in Diet Quality with Total and 
Cause-Specific Mortality. New England Journal of Medicine. 2017; 377: 143-153.

[18] Estruch R, Ros E, Salas-Salvadó J, Covas MI, Corella D, Arós $\mathrm{F}$, et al. Primary Prevention of Cardiovascular Disease with a Mediterranean Diet. New England Journal of Medicine. 2013; 368: 1279-1290.

[19] Park SY, Shvetsov YB, Kang M, Setiawan VW, Wilkens LR, Le Marchand L, et al. Changes in Diet Quality over 10 Years are Associated with Baseline Sociodemographic and Lifestyle Factors in the Multiethnic Cohort Study. The Journal of Nutrition. 2020; 150: 1880-1888.

[20] Zhang H, Zeng Y, Yang H, Hu Y, Hu Y, Chen W, et al. Familial factors, diet, and risk of cardiovascular disease: a cohort analysis of the UK Biobank. The American Journal of Clinical Nutrition. 2021; 114: 1837-1846.

[21] Iqbal R, Anand S, Ounpuu S, Islam S, Zhang X, Rangarajan S, et al. Dietary Patterns and the Risk of Acute Myocardial Infarction in 52 Countries: results of the INTERHEART study. Circulation. 2008; 118: 1929-1937.

[22] Rees K, Takeda A, Martin N, Ellis L, Wijesekara D, Vepa A, et $a l$. Mediterranean-style diet for the primary and secondary prevention of cardiovascular disease. Cochrane Database of Systematic Reviews. 2019; 3: CD009825.

[23] Monteiro CA, Cannon G, Moubarac JC, Levy RB, Louzada MLC, Jaime PC. The UN Decade of Nutrition, the NOVA food classification and the trouble with ultra-processing. Public Health Nutrition. 2018; 21: 5-17.

[24] Zhang Z, Jackson SL, Martinez E, Gillespie C, Yang Q. Association between ultraprocessed food intake and cardiovascular health in us adults: a cross-sectional analysis of the NHANES 2011-2016. The American Journal of Clinical Nutrition. 2021; 113: 428-436.

[25] Juul F, Vaidean G, Lin Y, Deierlein AL, Parekh N. UltraProcessed Foods and Incident Cardiovascular Disease in the Framingham Offspring Study. Journal of the American College of Cardiology. 2021; 77: 1520-1531.

[26] Iqbal R, Dehghan M, Mente A, Rangarajan S, Wielgosz A, Avezum A, et al. Associations of unprocessed and processed meat intake with mortality and cardiovascular disease in 21 countries [Prospective Urban Rural Epidemiology (PURE) Study]: a prospective cohort study. The American Journal of Clinical Nutrition. 2021; 114: 1049-1058.

[27] Juul F, Vaidean G, Parekh N. Ultra-processed Foods and Cardiovascular Diseases: Potential Mechanisms of Action. Advances in Nutrition. 2021; 12: 1673-1680.

[28] Kim H, Caulfield LE, Garcia-Larsen V, Steffen LM, Coresh J, Rebholz CM. Plant-Based Diets are Associated with a Lower Risk of Incident Cardiovascular Disease, Cardiovascular Disease Mortality, and all-Cause Mortality in a General Population of Middle-Aged Adults. Journal of the American Heart Association. 2019; 8: e012865.

[29] Satija A, Bhupathiraju SN, Spiegelman D, Chiuve SE, Manson JE, Willett W, et al. Healthful and Unhealthful Plant-Based Diets and the Risk of Coronary Heart Disease in U.S. Adults. Journal of the American College of Cardiology. 2017; 70: 411-422.

[30] Larsson SC, Wolk A. Potato consumption and risk of cardiovascular disease: 2 prospective cohort studies. The American Journal of Clinical Nutrition. 2016; 104: 1245-1252.

[31] Naghshi S, Sadeghi O, Willett WC, Esmaillzadeh A. Dietary intake of total, animal, and plant proteins and risk of all cause, cardiovascular, and cancer mortality: systematic review and doseresponse meta-analysis of prospective cohort studies. British Medical Journal. 2020; 370: m2412.

[32] Chuang SC, Norat T, Murphy N, Olsen A, Tjønneland A, Overvad K, et al. Fiber intake and total and cause-specific mortality in the European Prospective Investigation into Cancer and $\mathrm{Nu}-$ trition cohort. The American Journal of Clinical Nutrition. 2012; 96: 164-174.
[33] Partula V, Deschasaux M, Druesne-Pecollo N, Latino-Martel P, Desmetz E, Chazelas E, et al. Associations between consumption of dietary fibers and the risk of cardiovascular diseases, cancers, type 2 diabetes, and mortality in the prospective NutriNetSante cohort. The American Journal of Clinical Nutrition. 2020; 112: 195-207.

[34] AlEssa HB, Cohen R, Malik VS, Adebamowo SN, Rimm EB, Manson JE, et al. Carbohydrate quality and quantity and risk of coronary heart disease among us women and men. The American Journal of Clinical Nutrition. 2018; 107: 257-267.

[35] Zong G, Gao A, Hu FB, Sun Q. Whole Grain Intake and Mortality from all Causes, Cardiovascular Disease, and Cancer: A Meta-Analysis of Prospective Cohort Studies. Circulation. 2016; 133: $2370-2380$

[36] Martínez-González MA, Fernandez-Lazaro CI, Toledo E, DíazLópez A, Corella D, Goday A, et al. Carbohydrate quality changes and concurrent changes in cardiovascular risk factors: a longitudinal analysis in the PREDIMED-Plus randomized trial. The American Journal of Clinical Nutrition. 2020; 111: 291316.

[37] Ferreira H, Vasconcelos M, Gil AM, Pinto E. Benefits of pulse consumption on metabolism and health: a systematic review of randomized controlled trials. Critical Reviews in Food Science and Nutrition. 2021; 61: 85-96.

[38] Musa-Veloso K, Noori D, Venditti C, Poon T, Johnson J, Harkness LS, et al. A Systematic Review and Meta-Analysis of Randomized Controlled Trials on the Effects of Oats and Oat Processing on Postprandial Blood Glucose and Insulin Responses. The Journal of Nutrition. 2021; 151: 341-351.

[39] Seidelmann SB, Claggett B, Cheng S, Henglin M, Shah A, Steffen LM, et al. Dietary carbohydrate intake and mortality: a prospective cohort study and meta-analysis. The Lancet Public Health. 2018; 3: e419-e428.

[40] Blaak EE, Riccardi G, Cho L. Carbohydrates: Separating fact from fiction. Atherosclerosis. 2021; 328: 114-123.

[41] Jardine MA, Kahleova H, Levin SM, Ali Z, Trapp CB, Barnard ND. Perspective: Plant-Based Eating Pattern for Type 2 Diabetes Prevention and Treatment: Efficacy, Mechanisms, and Practical Considerations. Advances in Nutrition. 2021. (in press)

[42] Mazidi M, Katsiki N, Mikhailidis DP, Sattar N, Banach M. Lower carbohydrate diets and all-cause and cause-specific mortality: a population-based cohort study and pooling of prospective studies. European Heart Journal. 2019; 40: 2870-2879.

[43] Yang Q, Zhang Z, Gregg EW, Flanders WD, Merritt R, Hu FB. Added Sugar Intake and Cardiovascular Diseases Mortality among us Adults. JAMA Internal Medicine. 2014; 174: 516524.

[44] Hirahatake KM, Jacobs DR, Shikany JM, Jiang L, Wong ND, Steffen LM, et al. Cumulative intake of artificially sweetened and sugar-sweetened beverages and risk of incident type 2 diabetes in young adults: the Coronary Artery Risk Development in Young Adults (CARDIA) Study. The American Journal of Clinical Nutrition. 2019; 110: 733-741.

[45] Yin J, Zhu Y, Malik V, Li X, Peng X, Zhang FF, et al. Intake of Sugar-Sweetened and Low-Calorie Sweetened Beverages and Risk of Cardiovascular Disease: a Meta-Analysis and Systematic Review. Advances in Nutrition. 2021; 12: 89-101.

[46] Sieri S, Agnoli C, Grioni S, Weiderpass E, Mattiello A, Sluijs I, et al. Glycemic index, glycemic load, and risk of coronary heart disease: a pan-European cohort study. The American Journal of Clinical Nutrition. 2020; 112: 631-643.

[47] Jenkins DJA, Dehghan M, Mente A, Bangdiwala SI, Rangarajan S, Srichaikul K, et al. Glycemic Index, Glycemic Load, and Cardiovascular Disease and Mortality. New England Journal of Medicine. 2021; 384: 1312-1322.

[48] Ludwig DS, Willett WC, Volek JS, Neuhouser ML. Dietary fat: from foe to friend? Science. 2018; 362: 764-770. 
[49] Wang DD, Li Y, Chiuve SE, Stampfer MJ, Manson JE, Rimm EB, et al. Association of Specific Dietary Fats with Total and Cause-Specific Mortality. JAMA Internal Medicine. 2016; 176 : $1134-1145$

[50] Li J, Guasch-Ferré M, Li Y, Hu FB. Dietary intake and biomarkers of linoleic acid and mortality: systematic review and metaanalysis of prospective cohort studies. The American Journal of Clinical Nutrition. 2020; 112: 150-167.

[51] Marklund M, Leander K, Vikström M, Laguzzi F, Gigante B, Sjögren P, et al. Polyunsaturated Fat Intake Estimated by Circulating Biomarkers and Risk of Cardiovascular Disease and allCause Mortality in a Population-Based Cohort of 60-Year-Old Men and Women. Circulation. 2015; 132: 586-594.

[52] Zong G, Li Y, Sampson L, Dougherty LW, Willett WC, Wanders $\mathrm{AJ}$, et al. Monounsaturated fats from plant and animal sources in relation to risk of coronary heart disease among us men and women. The American Journal of Clinical Nutrition. 2018; 107: 445-453.

[53] Wu JHY, Marklund M, Imamura F, Tintle N, Ardisson Korat AV, de Goede J, et al. Omega- 6 fatty acid biomarkers and incident type 2 diabetes: pooled analysis of individual-level data for 39 740 adults from 20 prospective cohort studies. Lancet Diabetes Endocrinol. 2017; 5: 965-974.

[54] Julibert A, Bibiloni MDM, Tur JA. Dietary fat intake and metabolic syndrome in adults: a systematic review. Nutrition, Metabolism and Cardiovascular Diseases. 2019; 29: 887-905.

[55] Carson JAS, Lichtenstein AH, Anderson CAM, Appel LJ, KrisEtherton PM, Meyer KA, et al. Dietary Cholesterol and Cardiovascular Risk: a Science Advisory from the American Heart Association. Circulation. 2020; 141: e39-e53.

[56] Griffin BA, Mensink RP, Lovegrove JA. Does variation in serum LDL-cholesterol response to dietary fatty acids help explain the controversy over fat quality and cardiovascular disease risk? Atherosclerosis. 2021; 328: 108-113.

[57] Zhong VW, Van Horn L, Cornelis MC, Wilkins JT, Ning H, Carnethon MR, et al. Associations of Dietary Cholesterol or Egg Consumption with Incident Cardiovascular Disease and Mortality. The Journal of the American Medical Association. 2019; 321: 1081-1095.

[58] Key TJ, Appleby PN, Bradbury KE, Sweeting M, Wood A, Johansson I, et al. Consumption of Meat, Fish, Dairy Products, and Eggs and Risk of Ischemic Heart Disease. Circulation. 2019; 139: 2835-2845.

[59] Dehghan M, Mente A, Rangarajan S, Mohan V, Lear S, Swaminathan $\mathrm{S}$, et al. Association of egg intake with blood lipids, cardiovascular disease, and mortality in 177,000 people in 50 countries. The American Journal of Clinical Nutrition. 2020; 111: 795-803.

[60] Tang H, Cao Y, Yang X, Zhang Y. Egg Consumption and Stroke Risk: A Systematic Review and Dose-Response Meta-Analysis of Prospective Studies. Frontiers in Nutrition. 2020; 7: 153.

[61] Drouin-Chartier JP, Schwab AL, Chen S, Li Y, Sacks FM, Rosner B, et al. Egg consumption and risk of type 2 diabetes: findings from 3 large us cohort studies of men and women and a systematic review and meta-analysis of prospective cohort studies. The American Journal of Clinical Nutrition. 2020; 112: 619630.

[62] Greenberg JA, Jiang X, Tinker LF, Snetselaar LG, Saquib N, Shadyab AH. Eggs, dietary cholesterol, choline, betaine, and diabetes risk in the Women's Health Initiative: a prospective analysis. The American Journal of Clinical Nutrition. 2021; 114 : 368-377.

[63] Shin JY, Xun P, Nakamura Y, He K. Egg consumption in relation to risk of cardiovascular disease and diabetes: a systematic review and meta-analysis. The American Journal of Clinical Nutrition. 2013; 98: 146-159.

[64] Nestel PJ, Beilin LJ, Clifton PM, Watts GF, Mori TA. Practical Guidance for Food Consumption to Prevent Cardiovascular
Disease. Heart, Lung and Circulation. 2021; 30: 163-179.

[65] Zelniker TA, Morrow DA, Scirica BM, Furtado JD, Guo J, Mozaffarian D, et al. Plasma Omega-3 Fatty Acids and the Risk of Cardiovascular Events in Patients After an Acute Coronary Syndrome in MERLIN-TIMI 36. Journal of the American Heart Association. 2021; 10: e017401.

[66] Kalstad AA, Myhre PL, Laake K, Tveit SH, Schmidt EB, Smith $\mathrm{P}$, et al. Effects of n-3 Fatty Acid Supplements in Elderly Patients after Myocardial Infarction: A Randomized, Controlled Trial. Circulation. 2021; 143: 528-539.

[67] Bhatt DL, Steg PG, Miller M, Brinton EA, Jacobson TA, Ketchum SB, et al. Cardiovascular Risk Reduction with Icosapent Ethyl for Hypertriglyceridemia. New England Journal of Medicine. 2019; 380: 11-22.

[68] Bhatt DL, Steg PG, Miller M, Brinton EA, Jacobson TA, Ketchum SB, et al. Effects of Icosapent Ethyl on Total Ischemic Events: From REDUCE-IT. Journal of the American College of Cardiology. 2019; 73: 2791-2802.

[69] Yokoyama M, Origasa H, Matsuzaki M, Matsuzawa Y, Saito Y, Ishikawa Y, et al. Effects of eicosapentaenoic acid on major coronary events in hypercholesterolaemic patients (JELIS): a randomised open-label, blinded endpoint analysis. The Lancet. 2007; 369: 1090-1098.

[70] Nicholls SJ, Lincoff AM, Garcia M, Bash D, Ballantyne CM, Barter PJ, et al. Effect of High-Dose Omega-3 Fatty Acids vs Corn Oil on Major Adverse Cardiovascular Events in Patients at High Cardiovascular Risk: The STRENGTH Randomized Clinical Trial. The Journal of the American Medical Association. 2020; 324: 2268-2280.

[71] Olshansky B, Chung MK, Budoff MJ, Philip S, Jiao L, Doyle RT $\mathrm{Jr}$, et al. Mineral oil: safety and use as placebo in REDUCE-it and other clinical studies. European Heart Journal Supplements. 2020; 22: J34-J48.

[72] Mori TA, Woodman RJ. The independent effects of eicosapentaenoic acid and docosahexaenoic acid on cardiovascular risk factors in humans. Current Opinion in Clinical Nutrition \& Metabolic Care. 2006; 9: 95-104.

[73] Mori TA, Bao DQ, Burke V, Puddey IB, Beilin LJ. Docosahexaenoic Acid but not Eicosapentaenoic Acid Lowers Ambulatory Blood Pressure and Heart Rate in Humans. Hypertension. 1999; 34: $253-260$.

[74] Mori TA, Watts GF, Burke V, Hilme E, Puddey IB, Beilin LJ. Differential Effects of Eicosapentaenoic Acid and Docosahexaenoic Acid on Vascular Reactivity of the Forearm Microcirculation in Hyperlipidemic, Overweight Men. Circulation. 2000; 102: 1264-1269.

[75] Nissen SE, Lincoff AM, Wolski K, Ballantyne CM, Kastelein JJP, Ridker PM, et al. Association Between Achieved omega-3 Fatty Acid Levels and Major Adverse Cardiovascular Outcomes in Patients With High Cardiovascular Risk: A Secondary Analysis of the STRENGTH Trial. JAMA Cardiology. 2021; 6: 910917.

[76] Hu Y, Hu FB, Manson JE. Marine Omega-3 Supplementation and Cardiovascular Disease: an Updated Meta-Analysis of 13 Randomized Controlled Trials Involving 127477 Participants. Journal of the American Heart Association. 2019; 8: e013543.

[77] Khan SU, Lone AN, Khan MS, Virani SS, Blumenthal RS, Nasir K, et al. Effect of omega-3 fatty acids on cardiovascular outcomes: a systematic review and meta-analysis. EClinicalMedicine. 2021; 38: 100997.

[78] Jia X, Gao F, Pickett JK, Al Rifai M, Birnbaum Y, Nambi V, et al. Association between Omega-3 Fatty Acid Treatment and Atrial Fibrillation in Cardiovascular Outcome Trials: a Systematic Review and Meta-Analysis. Cardiovascular Drugs and Therapy. 2021; 35: 793-800.

[79] Jayedi A, Shab-Bidar S. Fish Consumption and the Risk of Chronic Disease: an Umbrella Review of Meta-Analyses of 
Prospective Cohort Studies. Advances in Nutrition. 2020; 11: 1123-1133.

[80] Mohan D, Mente A, Dehghan M, Rangarajan S, O’Donnell M, $\mathrm{Hu} \mathrm{W}$, et al. Associations of Fish Consumption with Risk of Cardiovascular Disease and Mortality among Individuals with or without Vascular Disease from 58 Countries. JAMA Internal Medicine. 2021; 181: 631-649.

[81] Fontecha J, Calvo MV, Juarez M, Gil A, Martínez-Vizcaino V. Milk and Dairy Product Consumption and Cardiovascular Diseases: an Overview of Systematic Reviews and Meta-Analyses. Advances in Nutrition. 2019; 10: S164-S189.

[82] Alexander DD, Bylsma LC, Vargas AJ, Cohen SS, Doucette A, Mohamed M, et al. Dairy consumption and CVD: a systematic review and meta-analysis. British Journal of Nutrition. 2016; 115: 737-750.

[83] Bechthold A, Boeing H, Schwedhelm C, Hoffmann G, Knüppel $\mathrm{S}$, Iqbal $\mathrm{K}$, et al. Food groups and risk of coronary heart disease, stroke and heart failure: a systematic review and dose-response meta-analysis of prospective studies. Critical Reviews in Food Science and Nutrition. 2019; 59: 1071-1090.

[84] Guo J, Astrup A, Lovegrove JA, Gijsbers L, Givens DI, Soedamah-Muthu SS. Milk and dairy consumption and risk of cardiovascular diseases and all-cause mortality: dose-response meta-analysis of prospective cohort studies. European Journal of Epidemiology. 2017; 32: 269-287.

[85] Cruijsen E, Jacobo Cejudo MG, Küpers LK, Busstra MC, Geleijnse JM. Dairy consumption and mortality after myocardial infarction: a prospective analysis in the Alpha Omega Cohort. The American Journal of Clinical Nutrition. 2021; 114: 59-69.

[86] Brassard D, Tessier-Grenier M, Allaire J, Rajendiran E, She Y, Ramprasath V, et al. Comparison of the impact of SFAs from cheese and butter on cardiometabolic risk factors: a randomized controlled trial. The American Journal of Clinical Nutrition. 2017; 105: 800-809.

[87] Chen M, Li Y, Sun Q, Pan A, Manson JE, Rexrode KM, et al. Dairy fat and risk of cardiovascular disease in 3 cohorts of us adults. The American Journal of Clinical Nutrition. 2016; 104 : 1209-1217.

[88] de Oliveira Otto MC, Mozaffarian D, Kromhout D, Bertoni AG, Sibley CT, Jacobs DR, et al. Dietary intake of saturated fat by food source and incident cardiovascular disease: the MultiEthnic Study of Atherosclerosis. The American Journal of Clinical Nutrition. 2012; 96: 397-404.

[89] Kvist K, Laursen ASD, Overvad K, Jakobsen MU. Substitution of Milk with whole-Fat Yogurt Products or Cheese is Associated with a Lower Risk of Myocardial Infarction: the Danish Diet, Cancer and Health cohort. The Journal of Nutrition. 2020; 150: 1252-1258.

[90] Sun Y, Liu B, Snetselaar LG, Wallace RB, Shadyab AH, Kroenke $\mathrm{CH}$, et al. Association of Major Dietary Protein Sources with all-Cause and Cause-Specific Mortality: Prospective Cohort Study. Journal of the American Heart Association. 2021; 10: e015553.

[91] Buziau AM, Soedamah-Muthu SS, Geleijnse JM, Mishra GD. Total Fermented Dairy Food Intake is Inversely Associated with Cardiovascular Disease Risk in Women. The Journal of Nutrition. 2019 ; 149: 1797-1804.

[92] Tognon G, Nilsson LM, Shungin D, Lissner L, Jansson JH, Renstrom F, et al. Nonfermented milk and other dairy products: associations with all-cause mortality. The American Journal of Clinical Nutrition. 2017; 105: 1502-1511.

[93] Patterson E, Larsson SC, Wolk A, Akesson A. Association between Dairy Food Consumption and Risk of Myocardial Infarc- tion in Women Differs by Type of Dairy Food. The Journal of Nutrition. 2013; 143: 74-79.

[94] Abete I, Romaguera D, Vieira AR, Lopez de Munain A, Norat T. Association between total, processed, red and white meat consumption and all-cause, CVD and IHD mortality: a metaanalysis of cohort studies. British Journal of Nutrition. 2014; 112: $762-775$.

[95] Micha R, Michas G, Mozaffarian D. Unprocessed Red and Processed Meats and Risk of Coronary Artery Disease and Type 2 Diabetes - an Updated Review of the Evidence. Current Atherosclerosis Reports. 2012; 14: 515-524.

[96] Micha R, Wallace SK, Mozaffarian D. Red and Processed Meat Consumption and Risk of Incident Coronary Heart Disease, Stroke, and Diabetes Mellitus: a systematic review and metaanalysis. Circulation. 2010; 121: 2271-2283.

[97] Song M, Fung TT, Hu FB, Willett WC, Longo VD, Chan AT, et al. Association of Animal and Plant Protein Intake with allCause and Cause-Specific Mortality. JAMA Internal Medicine. 2016; 176: 1453-1463.

[98] Sabaté J, Burkholder-Cooley NM, Segovia-Siapco G, Oda K, Wells B, Orlich MJ, et al. Unscrambling the relations of egg and meat consumption with type 2 diabetes risk. The American Journal of Clinical Nutrition. 2018; 108: 1121-1128.

[99] Zhong VW, Van Horn L, Greenland P, Carnethon MR, Ning H, Wilkins JT, et al. Associations of Processed Meat, Unprocessed Red Meat, Poultry, or Fish Intake with Incident Cardiovascular Disease and all-Cause Mortality. JAMA Internal Medicine. 2020; 180: 503-512.

[100] Aburto NJ, Ziolkovska A, Hooper L, Elliott P, Cappuccio FP, Meerpohl JJ. Effect of lower sodium intake on health: systematic review and meta-analyses. British Medical Journal. 2013; 346: f1326.

[101] Graudal N, Hubeck-Graudal T, Jürgens G, Taylor RS. Doseresponse relation between dietary sodium and blood pressure: a meta-regression analysis of 133 randomized controlled trials. The American Journal of Clinical Nutrition. 2019; 109: 1273 1278.

[102] Mente A, O'Donnell M, Rangarajan S, Dagenais G, Lear S, McQueen $\mathrm{M}$, et al. Associations of urinary sodium excretion with cardiovascular events in individuals with and without hypertension: a pooled analysis of data from four studies. The Lancet. 2016; 388: 465-475.

[103] Elijovich F, Weinberger MH, Anderson CA, Appel LJ, Bursztyn M, Cook NR, et al. Salt Sensitivity of Blood Pressure: A Scientific Statement from the American Heart Association. Hypertension. 2016; 68: e7-e46.

[104] He FJ, MacGregor GA. Role of salt intake in prevention of cardiovascular disease: controversies and challenges. Nature Reviews Cardiology. 2018; 15: 371-377.

[105] Stamler J, Chan Q, Daviglus ML, Dyer AR, Van Horn L, Garside DB, et al. Relation of Dietary Sodium (Salt) to Blood Pressure and its Possible Modulation by other Dietary Factors: The INTERMAP Study. Hypertension. 2018; 71: 631-637.

[106] Neal B, Wu Y, Feng X, Zhang R, Zhang Y, Shi J, et al. Effect of Salt Substitution on Cardiovascular Events and Death. New England Journal of Medicine. 2021; 385: 1067-1077.

[107] Khan SU, Khan MU, Riaz H, Valavoor S, Zhao D, Vaughan L, et al. Effects of Nutritional Supplements and Dietary Interventions on Cardiovascular Outcomes: An Umbrella Review and Evidence Map. Annals of Internal Medicine. 2019; 171: 190198.

[108] Ha K, Sakaki JR, Chun OK. Nutrient Adequacy Is Associated with Reduced Mortality in US Adults. The Journal of Nutrition. 2021; 151: 3214-3222. 